\title{
Rehabilitation of an important cultural and architectural heritage: the traditional adobe constructions in Aveiro district
}

\author{
D. Silveira, H. Varum \& A. Costa \\ Civil Engineering Department, University of Aveiro, Portugal
}

\begin{abstract}
Adobe is a low-cost construction material, locally available, presents excellent thermal and acoustic properties, and is associated to quite simple construction methods that only require a small consumption of energy. It is indeed an economically viable material, and its use respects the environmental equilibrium.

Rehabilitation and strengthening of existing traditional adobe constructions contribute to the quality of life improvement of those who use them and for an increase of associated safety levels, particularly if an effective seismic strengthening is assured. The preservation of these constructions also contributes for the recognition of the advantages that adobe, as a structural material, presents, encouraging its use in new constructions, and allowing for the reduction of the efforts and resources that are affected to new edifications that normally replace the adobe existing ones.

A research group at the University of Aveiro has been developing work aimed at the characterization of the vast traditional adobe constructed park of Aveiro district, which constitutes an important architectonic and cultural heritage. Studies on the composition and mechanical behaviour of adobe units and mortars, and on the structural behaviour of adobe masonry walls were conducted. These studies aim to establish a basis of knowledge that can support the interpretation of structural pathologies, calibration of numerical models, structural safety assessment, and design of strengthening solutions. This article presents and discusses the developed work, explaining how it can contribute for a more conscious development of rehabilitation practices.

Keywords: adobe constructions, cultural heritage, structural behaviour, seismic vulnerability, pathologies, rehabilitation, strengthening.
\end{abstract}




\section{Introduction}

In Portugal, earth construction was mainly used in south and littoral center. Rammed earth was more applied in south and adobe, despite its significant heterogeneity confirmed by the many different identified typologies, in littoral center, especially in Aveiro district $[1,2]$.

Deterioration and, in many cases, abandon of adobe constructions in Aveiro district constitute, more and more, a preoccupying reality. There still can be found, however, many constructions that are entirely capable of complying with the required functions, only demanding small maintenance and conservation measures. Demolition has, although, been the more frequently adapted solution, with rare exceptions. Only a few owners, sensible for the importance of protection and preservation of this patrimony, have promoted its strengthening and rehabilitation.

The rehabilitation of these edifications presents relevant difficulties, essentially due to the lack of information concerning properties and characteristics of the mechanical behaviour of adobe masonry. Technical studies for the determination of these properties and characteristics are thus demanded. The mechanical characterization of adobe masonry constitutes a fundamental instrument in the support of rehabilitation and strengthening projects, and even in the support of the design of new adobe constructions Hernandez et al [3].

\section{Adobe construction in the World}

Earth is one of the oldest and more widespread construction materials and adobe seems to be the earthen material that is primarily used. Earth houses are currently still being in use by millions of people in many countries around the World because of cultural, climatic and economic reasons.

It is estimated, according to Houben and Guillard [4], that about $30 \%$ of the World population lives in earth buildings, and also that about $50 \%$ of the developing countries population, including the majority of rural population and at least $20 \%$ of urban and marginal urban population, lives in earth buildings. In Peru, for example, about $60 \%$ of houses are constructed with adobe or with rammed earth, and in India, according to 1971 census, $73 \%$ of buildings were, in that time, constructed with earth (67 millions of houses inhabited by 374 millions of people).

Earth construction also presents an important expression in developed countries. According to North and Kanuka-Fuchs [5], in France, for example, about $15 \%$ of the population lives in houses with earth walls and, in some regions of Australia, about $20 \%$ of houses are constructed with earth walls. In occidental countries, during the last decades, many luxurious earth houses have been constructed, demonstrating the qualities and potential of this natural material, dissociating it from preconceptions like poverty and inferiority. 


\section{Adobe construction in Portugal}

In the near past, earth was a very common construction material in Portugal. Adobe and rammed earth were used through years in almost all types of construction, having this utilization declined during the first half of $20^{\text {th }}$ century, with the emergence of cement industry.

In Beira Litoral region, the two dominating earth construction methods in Portugal were widely applied. Mondego river establishes the border line between two reagions where these two methods were applied: adobe prevails at the north and rammed earth at the south.

Presently, according to information from the municipality, about $25 \%$ of the existing buildings in Aveiro city are made of adobe. It is estimated that this percentage rises to $40 \%$ when referred to the entire district, reflecting the importance of this construction system in rural areas. Adobe can be found in varied types of construction: rural and urban buildings, many of which are still inhabited, walls for the delimitation of properties, water wells, churches and warehouses, fig. 1. An important number of the urban adobe buildings are of cultural, historical and architectonic recognized value, namely of the "Art Nouveau" style.

The old Aveiro fire station building, the church of Quintãs, and the old flourmill building recently converted by the University of Aveiro into a space for science results diffusion, among many others, are just good examples of existing adobe buildings in Aveiro district with important socio-cultural value.
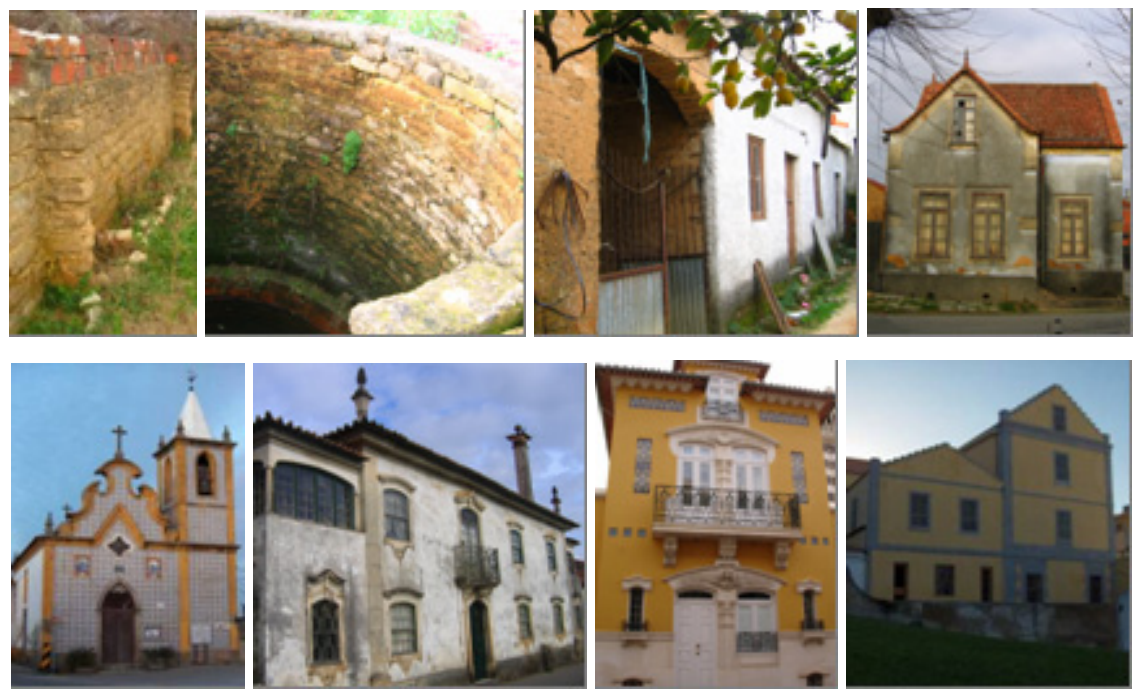

Figure 1: Examples of existing adobe constructions in Aveiro district. 


\section{Adobe performance as a construction material}

Adobe is a construction material that possesses many attractive characteristics. It is a low-cost material, locally available, presents excellent thermal and acoustic properties, and is associated to simple constructive methods, requiring reduced energy consumption. It is indeed an economically viable material, and its use respects the environmental equilibrium.

Adobe can also, however, present some disadvantages. Adobe traditional construction, if not properly designed and strengthened, may present a deficient response when subjected to cyclic actions, as those induced by earthquakes, suffering severe structural damage and frequently reaching collapse. Adobe construction, when not duly protected, is particularly vulnerable to deterioration. Water is one of its principal aggressors. Buildings, generally, do not have any design, and are constructed by non-specialized workers, which contributes for the large number of structural and non-structural anomalies within this type of buildings.

The use of earth construction is very common in some regions of the World where earthquake risk is very high, as in certain countries of Latin America, Africa, Asia (especially in India), Middle East and South of Europe. Several recent earthquakes affecting earth building have evidenced the seismic vulnerability associated to this type of construction, when not properly strengthened. The El Salvador earthquakes of January and February, 2001 and the Bam, Iran, earthquake of December 26, 2003 are just two significant examples. In El Salvador earthquakes more than one million people were made homeless, having the majority of the damage occurred in adobe houses.

\section{Structural safety assessment, rehabilitation and strengthening of the existing adobe constructions in Aveiro district: an urgent matter}

Portugal has been affected, in the last centuries, by several earthquakes of large and moderate intensity. Aveiro district is located in a region of moderate seismic hazard. However, due to the nature of the foundation soft soils, eventual earthquakes striking the region can be considerably amplified. Therefore, the seismic risk associated to the adobe constructions in Aveiro is not negligible.

The techniques adopted in the construction of adobe structures in Aveiro district were based in the accumulated experience, transmitted from generation to generation, which did not include a preoccupation with seismic safety, nor other concerns associated to actual functional and comfort exigencies. Thus, this constructed park is not properly reinforced to resist to seismic actions, nor duly conserved and adapted to modern exigencies, suffering of various structural and non-structural anomalies and deficiencies.

It is thus urgent to achieve a deep knowledge of the adobe constructed park, particularly in what concerns to its constitution, element dimensions, structural systems, pathologies and conservation state, with the principal objective of promoting its rehabilitation and strengthening. 
Rehabilitation and strengthening of existing traditional adobe constructions will contribute for quality of life improvement of those who use them and for an increase of associated safety levels, particularly if an effective seismic strengthening is assured. The preservation of this important architectonic and cultural heritage will also contribute for the recognition of the advantages that adobe, as a structural material, presents, encouraging its use in new constructions, and allowing for the reduction of the efforts and resources that are affected to new edifications that normally replace the adobe existing ones. This effort may have repercussions in all regions of Portugal where earth construction appears with a significant expression (namely in Beira Litoral, Algarve and Alentejo), but also in other parts of the World with similar constructive systems.

\section{Experimental work developed}

\subsection{Introduction}

A research group of the Civil Engineering Department, from the University of Aveiro, has been developing studies and experimental tests to aid filling the technical information gap concerning the structural behaviour of existing adobe constructions. Adobe units, taken from houses and land dividing walls, were characterized in terms of dimensions and granulometric composition. The mechanical characteristics of adobe units and mortar samples were investigated. Cylindrical adobe specimens cores were subjected to compression and splitting tests, and prismatic mortar specimens were subjected to compression tests. Small wallets, constructed at scale 1:3, with representative materials of those found in existing adobe constructions, were subjected to compression tests, perpendicularly and diagonally to the bed joints. The structural non-linear response of adobe walls has also been investigated in a series of full-scale tests, in the laboratory and in situ, with constant vertical load combined with imposed horizontal cyclic displacements.

\subsection{Mechanical characterization of adobe units, mortars and small wallets}

\subsubsection{Simple compression and splitting tests on adobe specimens}

In Aveiro district, adobe units present a large variability in what concerns to dimensions and constitution. Mechanical properties of adobe are therefore characterized by a significant heterogeneity. For the experimental testing campaign, it was selected a set of samples representative of different existing adobe construction typologies. Samples were collected from eight houses and eight land dividing walls, from different locations, in order to adequately characterize the mechanical behaviour of the material.

Cylindrical cores, with diameters ranging between 60 and $95 \mathrm{~mm}$, were extracted from the collected adobe samples units. These cylindrical cores had a height of approximately two times the diameter.

A total of 101 cylindrical specimens, 51 proceeding from houses and 50 from land dividing walls, were submitted to mechanical tests: 83 specimens were submitted to compression; and 18 to splitting tests, fig. 2 . 
The detailed description of the mechanical characterization testing campaign and of the obtained results can be found in $[6,7]$. The most relevant results are summarily presented in Section 6.2.4.

\subsubsection{Simple compression tests on mortar specimens}

10 mortar samples ( 2 from plaster and 8 from joints) taken from 3 different houses were submitted to compression tests, fig. 2 .

The load applied by the compression testing machine was transmitted through two square steel plates, with $40 \mathrm{~mm}$ side. It was obtained for the unconfined average strength: 1.68MPa (house 1); 1.07MPa (house 5); and, $0.45 \mathrm{MPa}$ (house 12).

\subsubsection{Compression tests on small wallets: perpendicular and diagonal to the bed joints}

To estimate the compression and shear strength of adobe traditional masonry walls, 13 small wallets with $17 \times 17 \times 10 \mathrm{~cm}$ were constructed and submitted to compression tests, perpendicular to the bed joints and diagonally, fig. 2.

The wallets were constructed at a reduced scale (1:3). For the construction of the wallets, prismatic blocks were extracted from adobe units taken from existing constructions, and a mortar with a composition similar to the one traditionally used was adopted.

The detailed description of the testing procedures and of the obtained results can be found in Varum et al [8]. The most relevant results of the mechanical behaviour characterization of the small wallets are summarily presented in Section 6.2.4.

\subsubsection{Analysis and interpretation of results}

The adobe specimens collected from existing constructions in Aveiro present significant compressive strength values, varying from 0.32 to $2.46 \mathrm{MPa}$. For each construction analysed, the tensile strength corresponds to approximately $20 \%$ of the compressive strength. Results for the analysed adobe samples reveal a clear tendency for samples with larger fractions of small dimension particles to present superior compressive and tensile strength values.

The compressive and shear strength obtained from compression tests on wallets are between 0.77 and $1.57 \mathrm{MPa}$; and between 0.05 and $0.19 \mathrm{MPa}$, respectively. For the wallets constituted by adobe units with a lower compressive strength, lower shear and compressive strengths were obtained.

Transversal modulus of elasticity and shear strength, for each series of tested wallets, are about $1 / 10$ of the corresponding modulus of elasticity and compressive strength evaluated in compression tests perpendicular to the bed joints.

\subsection{Tests on full-scale adobe masonry walls}

\subsubsection{Introduction}

It were conducted tests on adobe masonry wall specimens, one in laboratory and another in situ conditions, to characterize the mechanical behaviour of this masonry when subjected to cyclic actions, as those induced by earthquakes. 


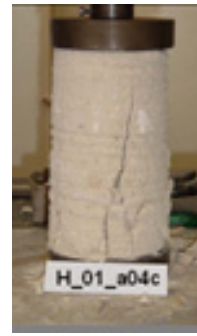

(a)

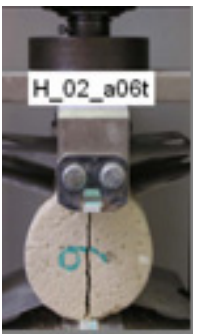

(b)

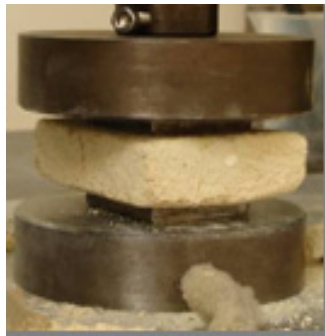

(c)

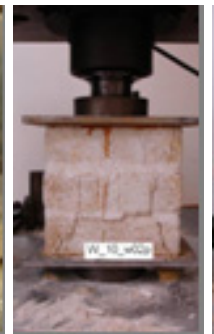

(d)

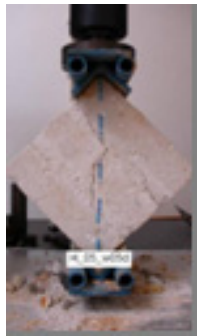

(e)

Figure 2: (a) simple compression test on adobe specimen; (b) splitting test on adobe specimen; (c) simple compression test on mortar specimen; (d) compression test on wallet perpendicular to the bed joints; and (e) compression test on wallet diagonal to the bed joints.

The wall tested in laboratory was subjected, initially, to a non-destructive dynamic test, to estimate the natural frequencies in each direction. These measured frequencies help on the dynamic characterization of the adobe masonry wall, and also on the calibration of numerical models. In a second phase, it was conducted a destructive test imposing constant vertical load combined with inplane horizontal cyclic forces. During the test, displacements were measured at four points on each side of the wall. In fig. 3 is presented a general scheme of the testing layout, including the wall specimen and the loading and displacements measuring systems.

The wall tested in situ was subjected to dynamic characterization tests, and to two horizontal cyclic mechanical tests, namely: an in-plane semi-destructive test and an out-of-plane destructive test.

The detailed description of the procedures and of the obtained results can be found in Varum et al [9].
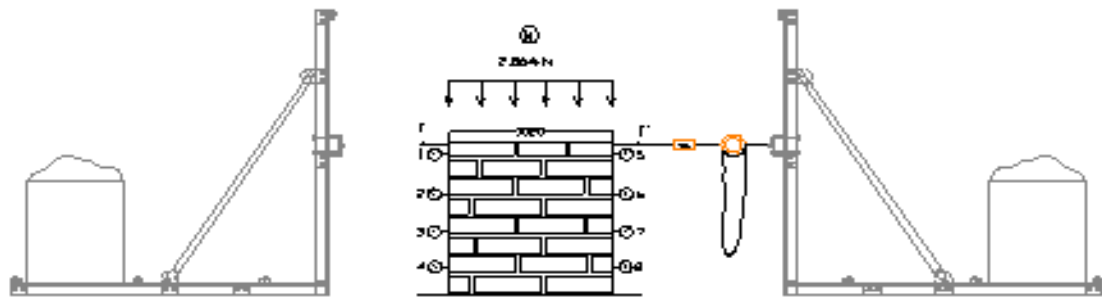

Figure 3: Laboratory testing layout: wall specimen; reaction frames; horizontal displacement transducers; dynamometer; and horizontal loading system.

\subsubsection{Laboratory test results}

The wall tested in the laboratory was constructed with units taken from an existing construction and with a mortar having a composition similar to the one traditionally used. The wall constructed and tested has the following dimensions: $1.08 \mathrm{~m}$ height, $1.02 \mathrm{~m}$ width and thickness of $0.185 \mathrm{~m}$. The boundary conditions at the base of the wall avoid lateral displacements and rotations. 
The natural frequencies in the two horizontal directions (transversal and longitudinal) were measured with a seismograph. A frequency of $10.94 \mathrm{~Hz}$ in the transversal direction was measured and, from it, an average modulus of elasticity of $316 \mathrm{MPa}$ was estimated. Subsequently, it was applied a vertical load of $2.86 \mathrm{kN}$ on the top of the wall, and in-plane horizontal forces were imposed, in cycles of increasing amplitude, till the collapse was reached. A maximum horizontal force of $3.2 \mathrm{kN}$ was applied. The failure mode was traduced by the opening of a horizontal crack at the base of the wall.

\subsubsection{In situ tests results}

The wall tested in situ conditions was firstly subjected to dynamic tests. A frequency of $2.20 \mathrm{~Hz}$ in the transversal direction was measured and, from it, an average modulus of elasticity of $101 \mathrm{MPa}$ was estimated.

For the cyclic tests on the wall it was not applied an additional vertical load. Initially, in-plane horizontal cyclic forces were imposed, in cycles of increasing amplitude. In a second phase, out-of-plane horizontal forces were applied to the wall, in cycles of increasing amplitude, but without inversion of the force signal, till the collapse was reached. A maximum horizontal force of $10.7 \mathrm{kN}$ was applied in-plane. This force was not raised to a higher level in order to allow performing the out-of-plane test. A maximum horizontal force of $0.69 \mathrm{kN}$ was applied out-of-plane. The failure mode observed is characterized by a rotation at the base, with damage spreaded through the wall height.

\section{Work in development and final considerations}

A group at the Civil Engineering Department from the University of Aveiro has been developing research projects focused in the rehabilitation and strengthening of the adobe constructed park of Aveiro district. The work developed was summarily presented in this paper. The following methodology, illustrated in fig. 4 when applied to a single construction, is being followed: (i) detailed survey of the existing constructions and of the commonest structural and non-structural pathologies; (ii) material mechanical characterization; (iii) structural characterization and evaluation of structural safety; (iv) development of nonstructural rehabilitation and structural strengthening solutions.

The development of this project aims to establish a basis of knowledge that can support the interpretation of pathologies, the structural safety assessment, and the design of rehabilitation and strengthening solutions. With these studies it is intended to contribute for the improvement of human populations' quality of life, towards the rehabilitation of their houses, taking into account the environmental equilibrium.

\section{Acknowledgements}

The authors express their acknowledgments to Tiago Martins, Henrique Pereira, João Almeida and Hugo Rodrigues for their collaboration in the experimental work here summarily presented, and to all persons that kindly opened their own houses for the study, samples collecting and testing on adobe constructions. 


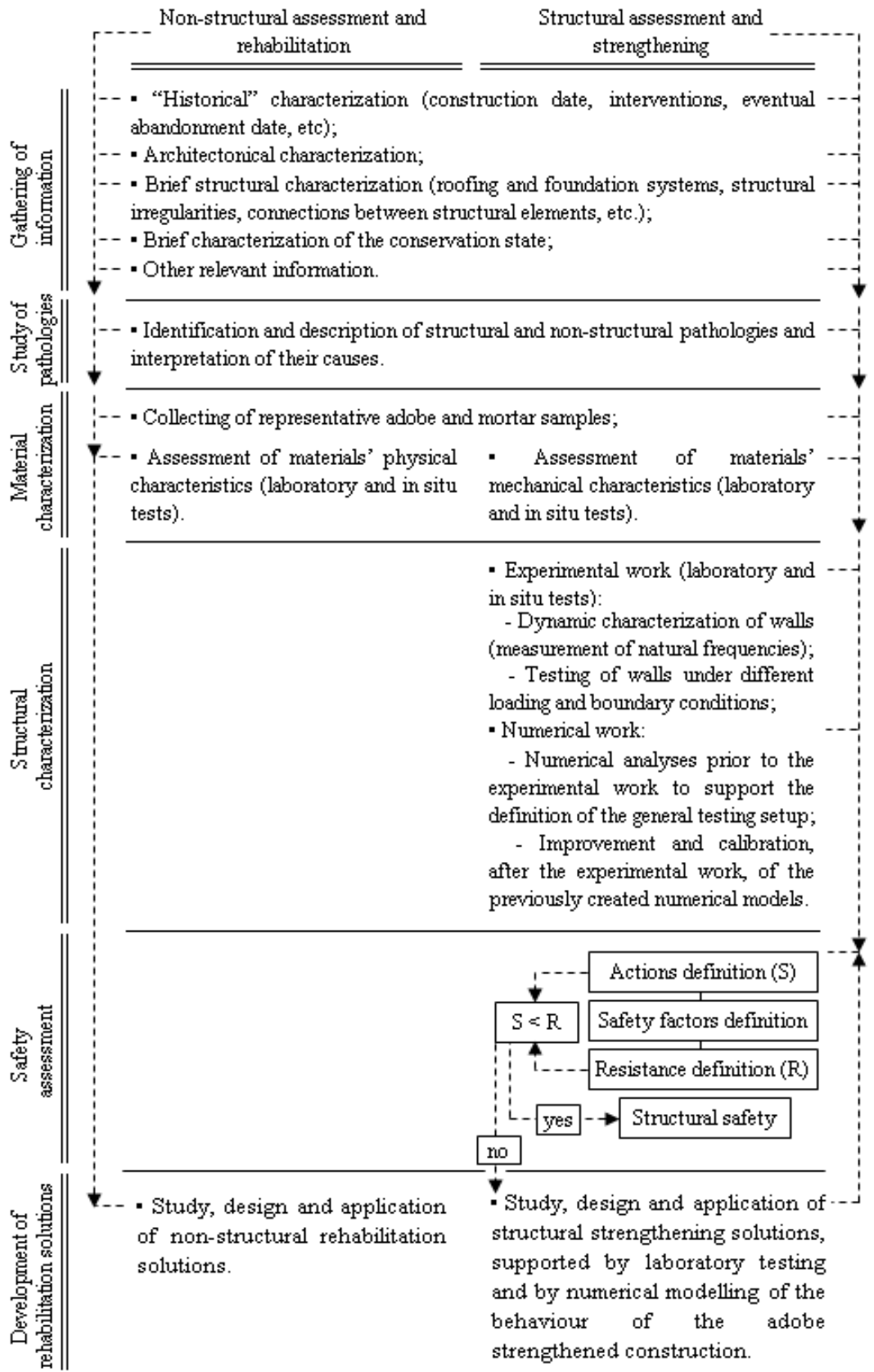

Figure 4: $\quad$ Methodology for the non-structural and structural evaluation of an existing adobe construction and the development of rehabilitation and strengthening solutions. 


\section{References}

[1] Oliveira, E.V. \& Galhano, F., Arquitectura tradicional portuguesa, Publicações D. Quixote: Lisbon, 1992.

[2] Proc. of Seminário Arquitecturas de Terra, eds. CCRCentro: Portugal, 1992.

[3] Hernandez, R.S., Barrios, M.S. \& Pozas, J.M.M., Characterization of ancient construction materials (mud walls and adobe) in the Churches of Cisneros, Villada and Boada de Campos (Palencia). Materiales de Construcción, 50(257), pp. 33-45, 2000.

[4] Houben, H. \& Guillaud, H., Earth construction - A comprehensive guide, ITDG Publishing: London, 1994.

[5] North, G. \& Kanuka-Fuchs, R., Waitakere City's Sustainable Home Guidelines - Earth building; Waitakere City Council. http:/www. waitakere.govt.nz/AbtCit/ec/bldsus/pdf/materials/earthbuilding.pdf).

[6] Varum, H., Martins, T. \& Velosa, A., Caracterização do adobe em construções existentes na região de Aveiro. Proc. of IV SIACOT Seminário Ibero-Americano de Construção com terra and III Seminário Arquitectura de Terra em Portugal, eds. ARGUMENTUM: Monsaraz, pp. 233-235, 2005.

[7] Varum, H., Costa, A., Pereira, H. \& Almeida, J., Ensaios de caracterização do comportamento estrutural de construções existentes em adobe. Proc. of V SIACOT Seminário Ibero-Americano de Construção com terra and I Seminario Argentino de Arquitectura y Construccion con tierra, eds. R. Mellace, J.A. Voltan, S.A. Cirvini, G.M. Viñuales, C.M. Neves, R. Rotondaro \& E. Montaña: Mendoza, pp. 73-74, 2006.

[8] Varum, H., Costa, A., Pereira, H. \& Almeida, J., Comportamento estrutural de elementos resistentes em alvenaria de adobe. Proc. of I Seminário Arquitetura e Construção com Terra no Brasil and IV Seminário Arquitectura de Terra em Portugal, Ouro Preto, pp. 1-8, 2006.

[9] Varum, H., Costa, A., Pereira, H., Almeida, J. \& Rodrigues, H., Avaliação experimental do comportamento estrutural de elementos resistentes em alvenaria de adobe. Proc. of III Congreso Internacional de Arquitectura en Tierra, Valladolid, 2006. 